\title{
DYNAMIC RESPONSES IMPROVEMENT OF GRID CONNECTED WPGS USING FLC IN HIGH WIND SPEEDS
}

\author{
Maziar izadbakhsh $^{1 *}$, Majid Gandomkar ${ }^{1}$, Alireza Rezvani ${ }^{1}$ and Saeed Vafaei ${ }^{1}$ \\ ${ }^{1}$ Department of Electrical Engineering, Saveh Branch, Islamic Azad University, Saveh, \\ Iran
}

\begin{abstract}
Environmental and sustainability concerns are developing the significance of distributed generation (DG) based on renewable energy sources. In this paper, dynamic responses investigation of grid connected wind turbine using permanent magnet synchronous generator (PMSG) under variable wind speeds and load circumstances is carried out. In order to control of turbine output power using Fuzzy Logic controller (FLC) in comparison with PI controller is proposed. Furthermore, the pitch angle based on FLC using wind speed and active power as inputs, can have faster responses, thereby leading to smoother power curves, enhancement of dynamic performance of wind turbine and prevention of mechanical damages to PMSG. Inverter adjusted the DC link voltage and active power is fed by d-axis and reactive power is fed by $q$-axis (using $P-Q$ control mode). Simulation of wind power generation system (WPGS) is carried out in Matlab/Simulink, and the results verify the correctness and feasibility of control strategy.
\end{abstract}

\section{Keywords}

Dynamic responses, FLC, Pitch Angle, PMSG, P-Q control

\section{INTRODUCTION}

Renewable energy systems are of significance as being modular, nature-friendly and domestic. Virtually, all regions of the world have renewable resources. By this point of view studies on renewable energies concentrate more attention. Solar energy and wind energy are the two renewable energy sources most common in use. Among those renewable energy sources, wind energy stands as a true alternative to conventional technologies for electricity generation. Wind energy also has the clean energy aspect which is especially important, considering the effects of global warming $[1,2]$. Fixed speed and variable speed wind turbine generator systems are emerging in the wind power industry, although the former is rarely considered for new installations. One of the major drawbacks of fixed speed wind turbine generator system is that it cannot capture maximum power from the wind. A few types of variable speed wind turbine generator systems are commercially available today. A PMSG is recognized as a promising technology to use as a wind generator in both the direct-drive system and the system using a simple single-stage gearbox. One of the major advantages is the high power density of this type of machine $[2,3]$.

Another advantage of variable wind turbines is the capability of maximum power point tracking (MPPT) from wind energy sources [4]. Variable speed wind turbines operate in two primary 
regions, below rated power and above rated power. When power production is below the rated power for the machine, the turbine operates at variable rotor speeds to capture the maximum amount of energy available in the wind $[5,6]$. In above-rated power conditions, the primary objective is to maintain a constant power output. This is generally achieved by holding the generator torque constant and varying the blade pitch angle. MPPT controller somehow changes the rotor speed according to variation of wind speed that the tip speed ratio (TSR) is maintained in optimum value.

One of the methods to reach the maximum power point (MPP) is pitch angle control (B). In high speeds wind the extra production of active power via wind turbine lead to increases consuming of reactive power in generator and in which case, it should utilizes the reactive power compensator for injecting reactive power that has extra cost too [7]. In the past, PIDs is used mostly in controllers design but, by introduction of fuzzy logic instead of PID, created a better performance and best preventative way to eliminate the profound mathematical understanding of system. In comparing PIDs and Fuzzy logic systems, fuzzy logic has more stability, faster and smoother response, smaller overshoot and does not need a fast processor, Also it's more powerful than other non-linear controllers $[8,9]$. Some authors have already presented on variable wind turbine using PMSG technology, including dynamic and transient characteristics [10, 11]. Various control strategies can be adopted for the operation of the generator and grid side converter, as proposed in $[11,12]$.

In these papers [13-15], pitch angle based on FLC is presented. In [15] active power and in [13, 14] both reactive power and rotational rotor speed are used as input signals and because in mentioned items wind speed's been ignored, the controller has not fast response and may cause mechanical damages to synchronous generator. Also, another problem in these articles that it is not practically connected to grid [14-18], but the grid connected mode in this paper is proposed to analyse the system performance. In recent years, many topologies based on power electronic devices with different level of complexity and cost is developed investigated in order to connect a PMSG to network. There are two modes for inverter operating: 1) Active and reactive control mode (P-Q control), 2) Voltage and frequency control mode (V-F control) [19, 20].

Analysis performance of grid connected PMSG wind turbine in P-Q control mode under load circumstances and variable wind speeds and also, enhancement of dynamic performance in WPGS using pitch angle based on FLC is investigated. P-Q control strategy is derived from Park transformation and it's simulated in Matlab software. The pitch angle is designed based on FLC by adding wind speed as an input signal to adjust the turbine output power in extra high speed.

\section{STURUCTURE OF GRID CONNECTED WPGS}

The diagram of a WPGS based on PMSG integrated to grid is illustrated in Figure 1. Turbine output is rectified by using uncontrolled rectifier. Then DC link voltage is adjusted by PI controller until it reaches a constant value and then, the constant voltage is inverted to AC voltage using sinusoidal PWM inverter. Inverter adjusted the DC link voltage and injected active power by $\mathrm{d}$-axis and injected reactive power by q-axis using PQ control method. Furthermore, turbine output is regulated through pitch angle based on FLC in extra high wind speeds. By increasing pitch angle via fuzzy controller, the exceeding power of wind turbine is limited, reaching to the nominal value and reducing inverter output current. Therefore, by the reduction of injected output power of wind turbine, the injection of extra total active power to grid is decreased. 


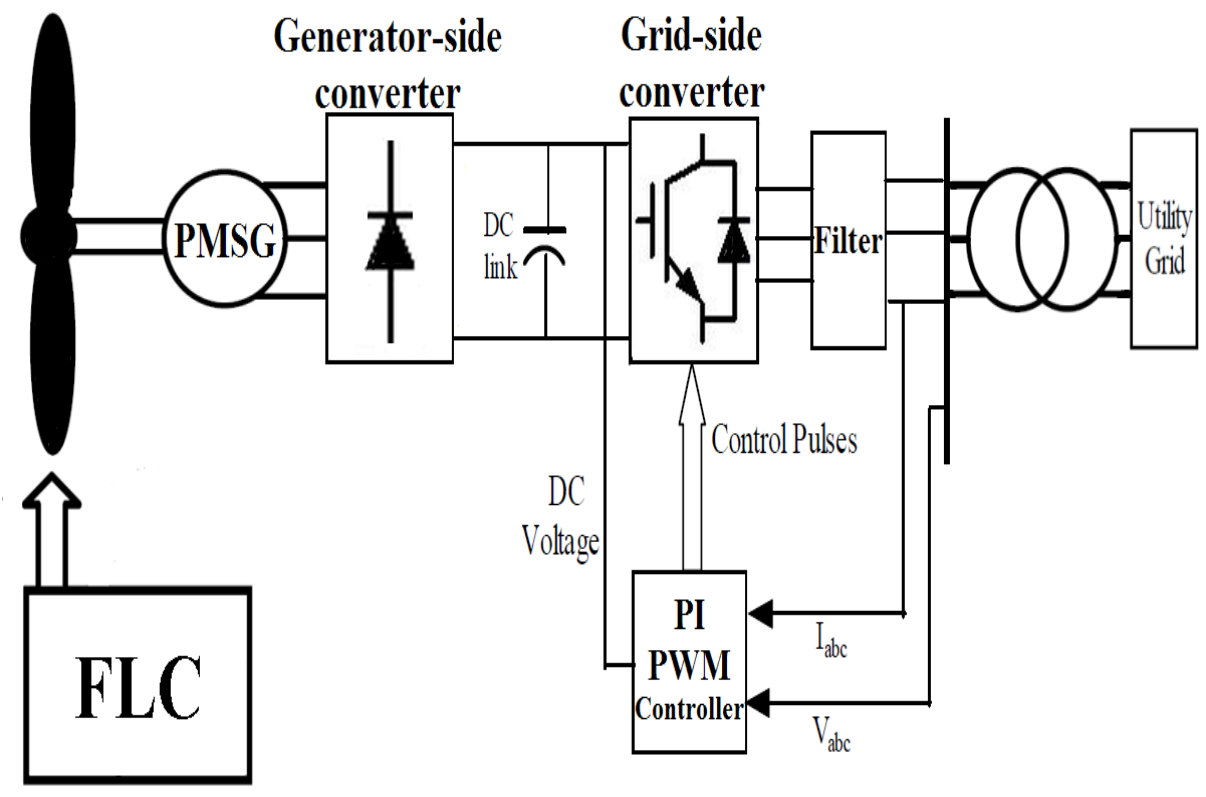

Figure 1. The block diagram of WPGS

\subsection{Variable Wind Turbine Modelling}

The amount of electricity that a turbine is able to produce depends on the speed of rotor and the speed of the wind that propels the rotor [21, 22]. Aerodynamic wind power is calculated in equation (1).

$$
\begin{aligned}
& \mathrm{P}=0.5 \rho \mathrm{AC}_{\mathrm{p}}(\lambda, \beta) \mathrm{V}_{\mathrm{w}}^{3} \\
& \lambda=\frac{\mathrm{W}_{m} R}{V_{w}}
\end{aligned}
$$

Where $\mathrm{P}, \rho, \mathrm{A}, \mathrm{V}_{\mathrm{w}}, \mathrm{W}_{\mathrm{m}}$ and $\mathrm{R}$ are power, air density, rotor swept area of the wind turbine, wind speed in $\mathrm{m} / \mathrm{sec}$, rotor speed in $\mathrm{rad} / \mathrm{sec}$ and radius of turbine respectively. Also, $\mathrm{C}_{\mathrm{p}}$ is the aerodynamic efficiency of rotor.

$$
\begin{aligned}
& \mathrm{C}_{\mathrm{p}}(\lambda, \beta)=0.5176\left(\frac{116}{\lambda_{i}}-0.4 \beta-5\right) e^{\frac{-21}{\lambda_{i}}} \\
& \lambda_{\mathrm{i}}=\left[\frac{1}{\lambda+0.08 \beta}-\frac{0.035}{\beta^{3}+1}\right]^{-1}
\end{aligned}
$$

Furthermore, the $\mathrm{C}_{\mathrm{p}}$ depends on TSR and blade pitch angle. Figure 2 shows the typical variation of $C_{p}$ respect to the TSR or various values of the pitch angle ( $\beta$ ) [23]. 


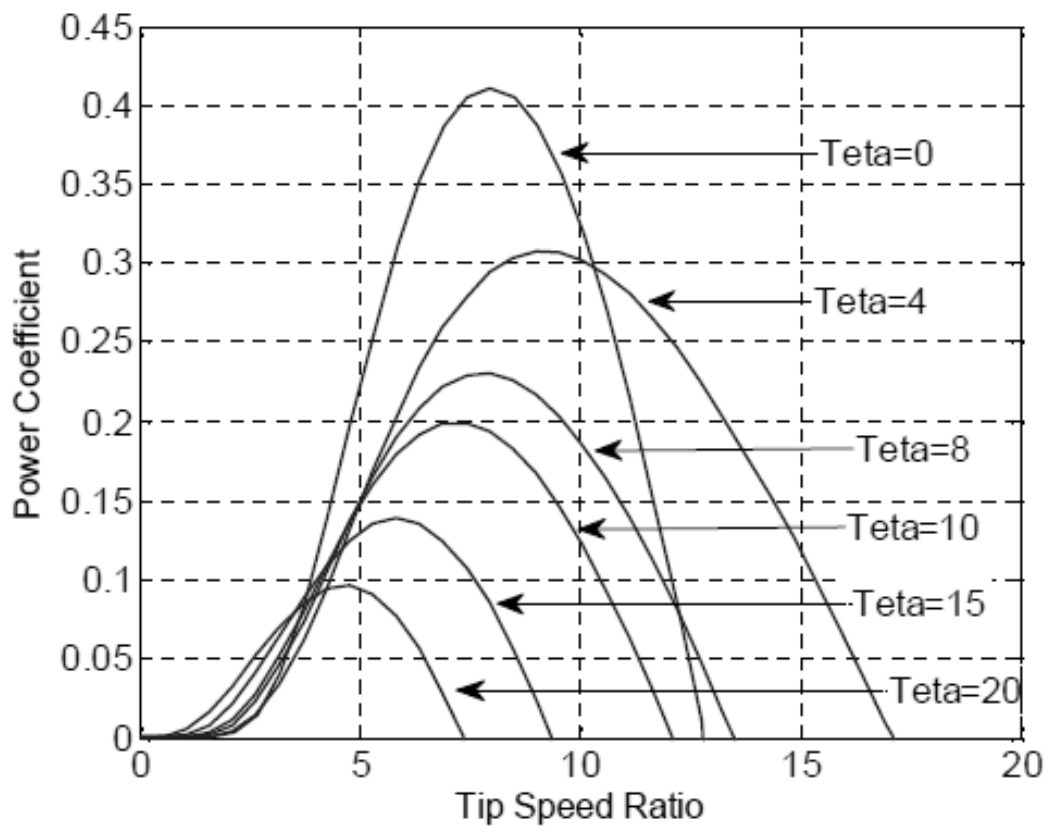

Figure 2. $C_{p}$ Vs $\lambda$ for various pitch angles $(\beta)$

\subsection{PMSG Modelling}

A synchronous generator with reference to Park's transformation is illustrated which d-axis is rotating along magnetic field direction. PMSG voltage equations are given by [24, 25]:

$$
\begin{aligned}
& \frac{\mathrm{di}_{\mathrm{ds}}}{\mathrm{dt}}=\frac{1}{\mathrm{~L}_{\mathrm{d}}}\left[-\mathrm{V}_{\mathrm{ds}}-\mathrm{R}_{\mathrm{s}} \mathrm{i}_{\mathrm{ds}}+\omega \mathrm{L}_{\mathrm{q}} \mathrm{i}_{\mathrm{qs}}\right] \\
& \frac{\mathrm{di}_{\mathrm{qs}}}{\mathrm{dt}}=\frac{1}{\mathrm{~L}_{\mathrm{q}}}\left[-\mathrm{V}_{\mathrm{qs}}-\mathrm{R}_{\mathrm{s}} \mathrm{i}_{\mathrm{qs}}-\omega \mathrm{L}_{\mathrm{d}} \mathrm{i}_{\mathrm{ds}}+\omega \phi_{\mathrm{m}}\right]
\end{aligned}
$$

Where $\mathrm{V}_{\mathrm{ds}}$ and $\mathrm{V}_{\mathrm{qs}}$ are $\mathrm{d}$ and $\mathrm{q}$ axis machine voltages and $\mathrm{I}_{\mathrm{ds}}$ and $\mathrm{I}_{\mathrm{qs}}$ are $\mathrm{d}$ and $\mathrm{q}$ axis machine currents, $\mathrm{R}_{\mathrm{s}}$ : Stator Resistance, W: electrical angular frequency, $\mathrm{L}_{\mathrm{d}}$ : $\mathrm{d}$ axis inductance, $\mathrm{L}_{\mathrm{q}}: \mathrm{q}$ axis inductance, $\phi_{\mathrm{m}}$ : amplitude of the flux linkage caused by permanent magnet. If rotor is cylindrical $\left(\mathrm{L}_{\mathrm{d}} \approx \mathrm{L}_{\mathrm{q}}=\mathrm{L}_{\mathrm{s}}\right)$, the electromagnetic torque equation written as following:

$$
\mathrm{T}_{\mathrm{e}}=\frac{3}{2} p \phi_{m} i_{q s}
$$

Where, $\mathrm{p}$ is the number of pole pairs of the PMSG [26, 27].

\subsection{Pitch Angle Based on FLC}

FLC is made of three parts which is demonstrated in Figure 3. First part is fuzzification which is the process of changing a real scalar value into a fuzzy set. Second part is fuzzy inference motor that combines IF-THEN statements based on fuzzy principle and third part is defuzzification 
which is the process that changes a fuzzy set into a real value in output $[28,29]$.

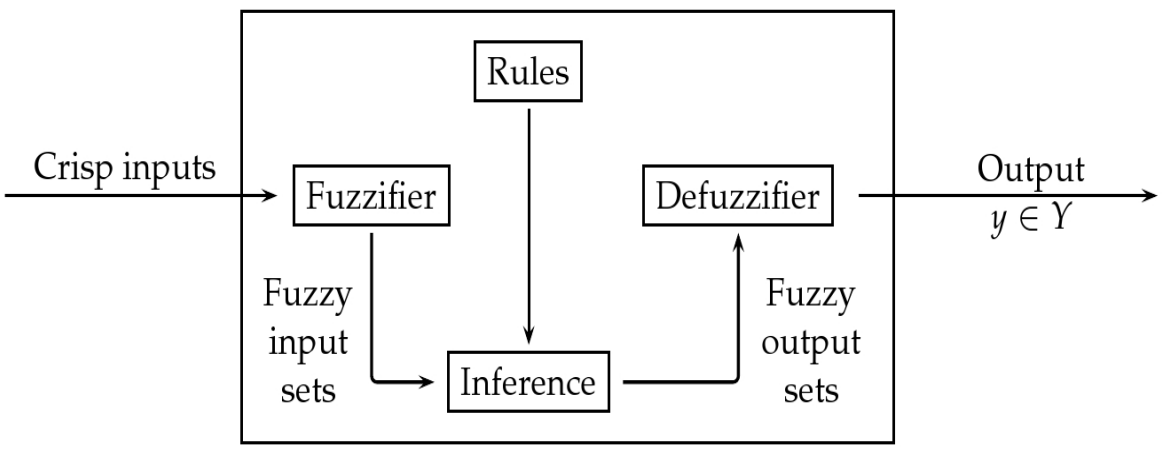

Figure 3. The Structure of FLC System

Proposed FLC is consisting of two input signal and one output signal. The first input signal is based on deviation between active power from the rated value in P.U and it's mentioned as error signal. Thus, positive value indicate turbine's normal operation and negative value shows the extra power generation during above rated wind speed. In this case, controller should modify in pitch angle degree which is done by increase the nominal value. The pitch angle degree is regulated on zero in a normal condition, the whole wind energy can be converted to mechanical energy and when the pitch angle start to increase from zero value, the wind attach angle to blades is increase that lead to aerodynamic power reduction and consequently the output power is draw down. Besides, the second signal taken from anemometer which is located on top of nacelle.

Controller's response is so faster when wind speed is used as an input signal comparing to the time that inputs are rotor rotational speed, reactive power and active power in large turbines with high moment of inertia [13-15]. However, mechanical erosion in large and high speed turbines is diminished by adjusting the FLC. Designing of pitch angle based on FLC for wind turbine power adjustment in high wind speeds, is being proposed. By increasing pitch angle via fuzzy controller, the exceeding power of wind turbine is limited, reaching to the nominal value. Three Trapezoidal membership functions are considered in this paper. Also Min-Max method is used as a defuzzification reference mechanism for centroid. Given membership functions are shown in Figure 4.

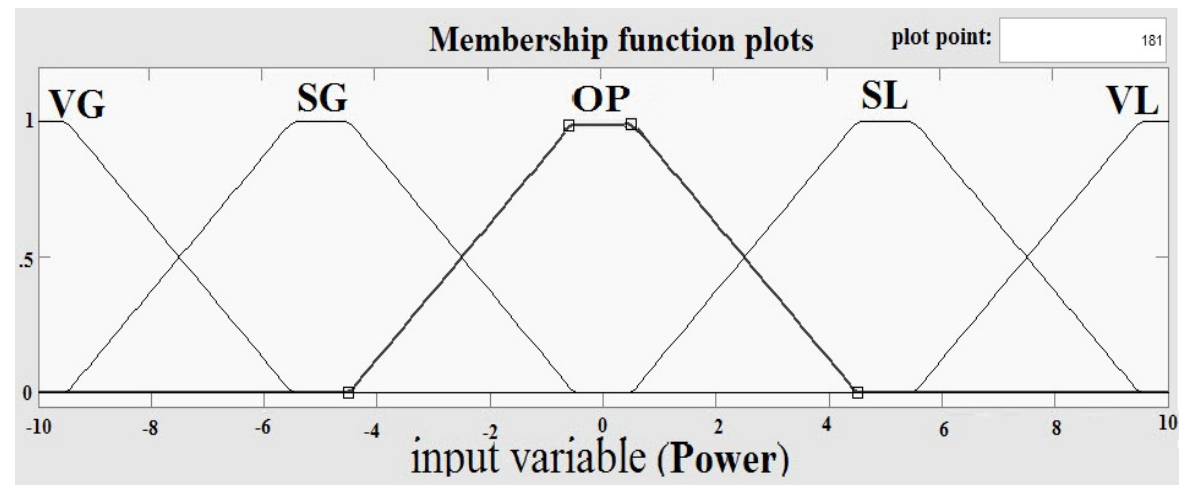

(a) 


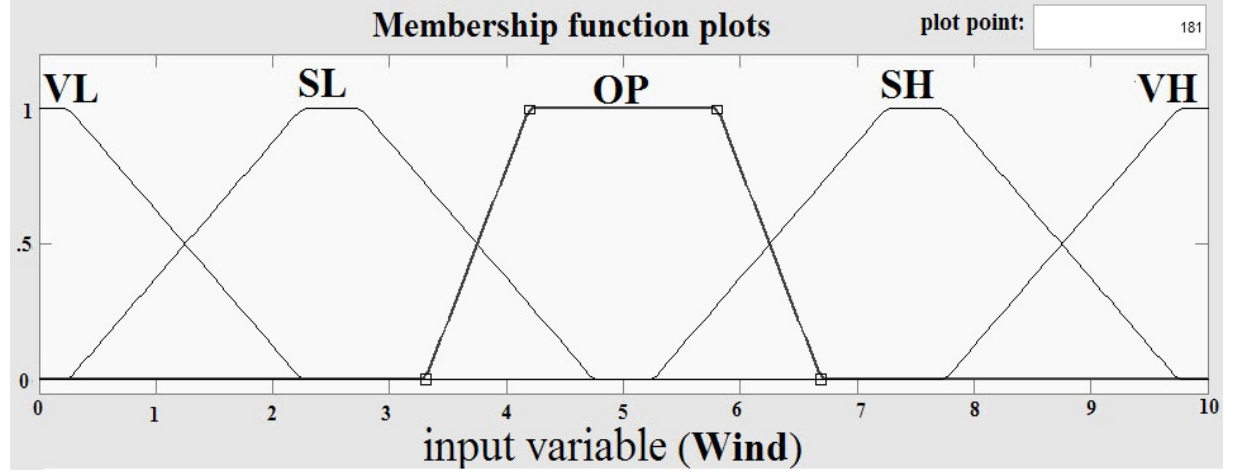

(b)

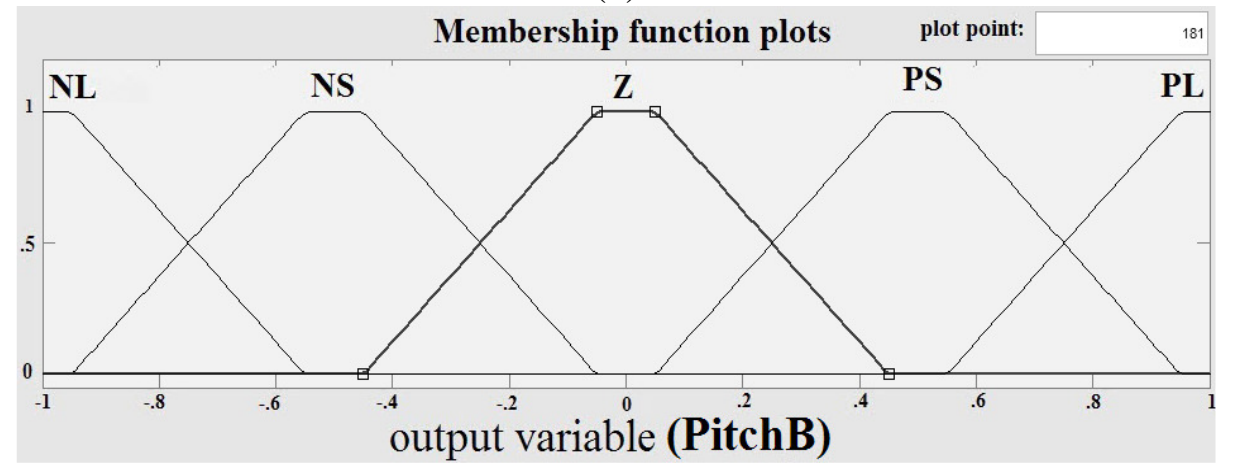

(c)

Figure 4. The membership function of fuzzy logic: (a) Membership functions of active power (error signal), (b) Membership functions of wind speed, (c) Membership functions of output ( $\beta$ )

Also, the rules are implemented to obtain require pitch angle are shown in Table 1. Where the linguistic variables are represented by VG(very great), SG (small great), OP (optimum), SL (small low) and VL (very low) for error signal and VL (very low),SL (small low), OP (optimum), SH (small high) and VH (very high) for wind speed signal and for output signal NL (negative large), NS (negative small), Z (zero),PS (positive small) and PL (positive large), respectively. Figure 5 Shows the three dimensional curve of inputs and output.

Table 1. Fuzzy rules

\begin{tabular}{|c|c|c|c|c|c|c|}
\hline \multicolumn{2}{|c|}{ Pitch command } & \multicolumn{5}{|c|}{ Active power (Error) } \\
\hline \multirow{6}{*}{$\begin{array}{l}\text { Wind } \\
\text { speed }\end{array}$} & & VG & SG & OP & SL & VL \\
\hline & VL & PL & PS & $\mathrm{Z}$ & $\mathrm{Z}$ & $\mathrm{Z}$ \\
\hline & SL & $\mathrm{PL}$ & PS & $\mathrm{Z}$ & $\mathrm{Z}$ & $\mathrm{Z}$ \\
\hline & $\mathrm{OP}$ & $\mathrm{PL}$ & PS & $\mathrm{Z}$ & $\mathrm{Z}$ & $\mathrm{Z}$ \\
\hline & $\mathrm{SH}$ & PL & PS & PS & PS & PS \\
\hline & $\mathrm{VH}$ & PL & PL & PL & PL & PL \\
\hline
\end{tabular}




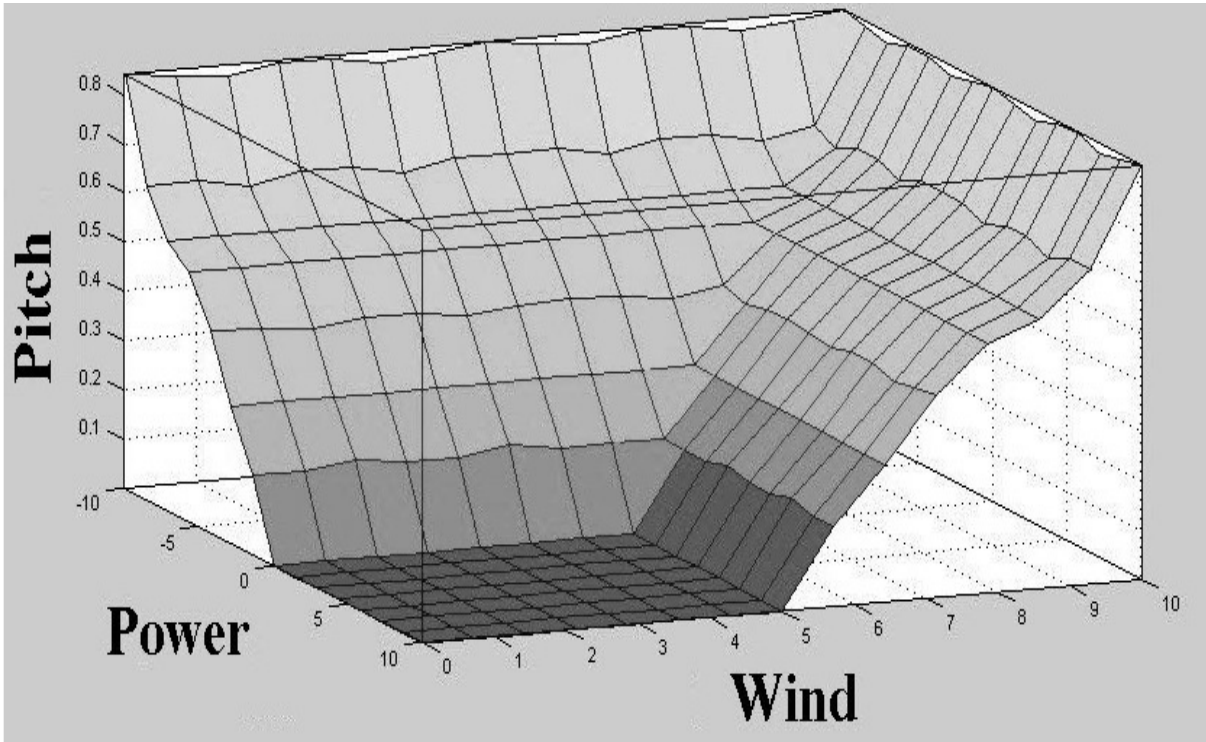

Figure 5. The three dimensional curve in fuzzy logic

\section{INVERTER CONTROL STRATEGY (P-Q)}

A three phase DC-AC voltage source inverter (VSI) is used for grid connection via pulse width modulation (PWM) technic. By applying inverter via PWM technic produces high frequency harmonics which lead to filter and eliminate the harmonics. The VSI can play role as an ideal sinusoidal voltage source.

Since wind power is fluctuates due to wind velocity, output voltage and frequency change continuously. A bridge rectifier provides AC to DC and then DC link voltage using PI controller to obtain constant value, then DC voltage will be inverted to get desired AC voltage [20].

$$
\begin{aligned}
& \mathrm{P}=\frac{3}{2}\left(V_{g d} I_{d}+V_{g q} I_{q}\right) \\
& \mathrm{Q}=\frac{3}{2}\left(V_{g q} I_{d}-V_{g d} I_{q}\right)
\end{aligned}
$$

If synchronous frame is synchronized with grid voltage, voltage vector is $\mathrm{V}=\mathrm{V}_{\mathrm{gd}}+\mathrm{j} 0$ which active and reactive power may be as following:

$$
\begin{aligned}
& \mathrm{P}=\frac{3}{2} V_{g d} I_{d} \\
& \mathrm{Q}=\frac{3}{2} V_{g d} I_{q}
\end{aligned}
$$

Synchronous reference is calculate quantities of d-axis, q-axis and zero sequence in two axis rotational reference vector for three phase sinusoidal signal illustrated in Figure 6 . The equations are given by (12), (13). 


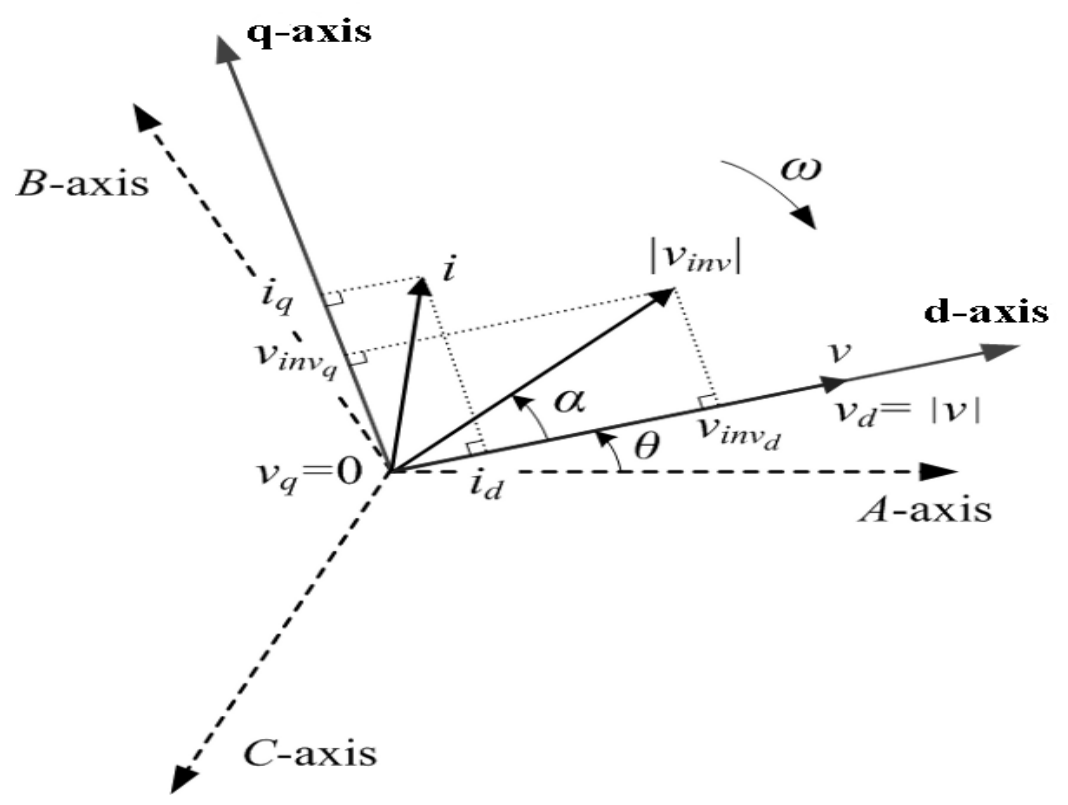

Figure 6. The synchronous reference machine

$$
\begin{aligned}
& {\left[\begin{array}{c}
\mathrm{V}_{\mathrm{d}} \\
\mathrm{V}_{\mathrm{q}} \\
\mathrm{V}_{0}
\end{array}\right]=\mathrm{C}\left[\begin{array}{c}
\mathrm{V}_{\mathrm{a}} \\
\mathrm{V}_{\mathrm{b}} \\
\mathrm{V}_{\mathrm{c}}
\end{array}\right],\left[\begin{array}{l}
\mathrm{i}_{\mathrm{d}} \\
\mathrm{i}_{\mathrm{q}} \\
\mathrm{i}_{0}
\end{array}\right]=\mathrm{C}\left[\begin{array}{c}
\mathrm{i}_{\mathrm{a}} \\
\mathrm{i}_{\mathrm{b}} \\
\mathrm{i}_{\mathrm{c}}
\end{array}\right]} \\
& \mathrm{C}_{\mathrm{dq} 0}=\frac{2}{3}\left[\begin{array}{ccc}
\cos \theta & \cos (\theta-2 \pi / 3) & \cos (\theta+2 \pi / 3) \\
-\sin \theta & -\sin (\theta-2 \pi / 3) & -\sin (\theta+2 \pi / 3) \\
\frac{1}{2} & \frac{1}{2} & \frac{1}{2}
\end{array}\right]
\end{aligned}
$$

Inverter control model is illustrated in Figure 7. The target of grid side controller is to keep the DC link voltage in constant value, regardless of power amplitude. Inverter control strategy is consisting of two control loops. Internal control loop is control the grid current and external control loop is control the voltage. Internal control loop which is responsible for power quality such as low total harmonic distortion (THD) and improvement of power quality and external control loop is responsible for balancing the power.

One of the most important characteristics of P-Q control loop is the capability of independent performance of grid. Another benefit of this mode is increasing operational reliability and power quality. The external loop capacitor voltage control is used to set reference current for d-axis in order to control active power. The q-axis reference current is allocated to inverter output reactive power [25]. If power factor is unit, therefore this current will be zero. The phase locked loop (PLL) blocks which measure the voltage phase angle $\theta_{\mathrm{g}}$ is based on Park transformation and also synchronize the inverter to grid [30]. 


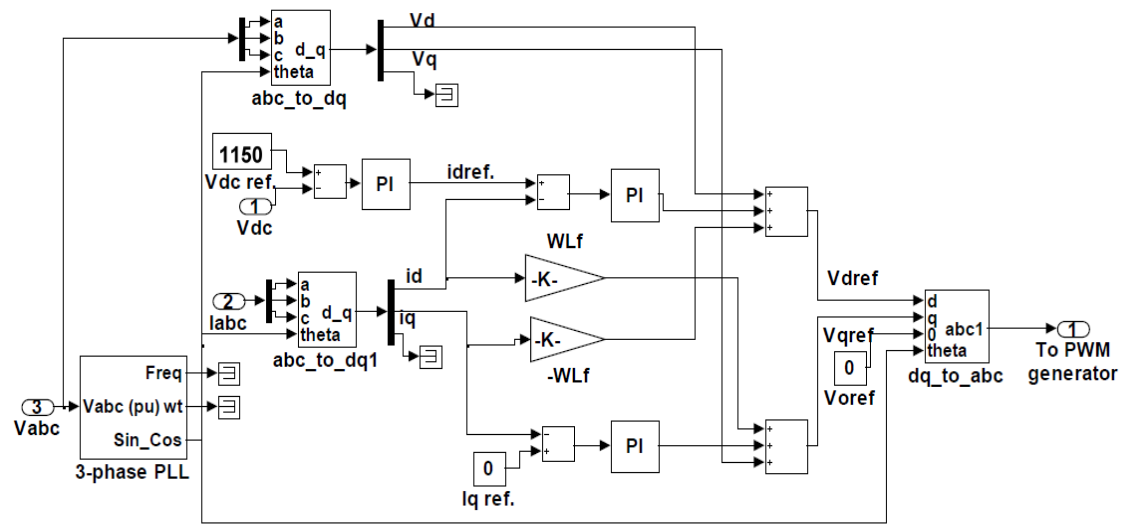

Figure 7. The inverter control model

\section{SIMULATION RESULTS}

In this section, simulation results under different terms of operation using Matlab/Simulink are presented. System block diagram is shown in Figure 8.

PMSG parameters: Stator resistance per phase: $2.5 \Omega$, Inertia: $0.82 \mathrm{e}^{-3} \mathrm{~kg}-\mathrm{m}^{2}$, Torque constant: $12 \mathrm{~N}-\mathrm{M} / \mathrm{A}$, Pole pairs: 8, Output power: $90 \mathrm{~kW}$, Nominal speed: $12 \mathrm{~m} / \mathrm{s}, \mathrm{L}_{\mathrm{d}}=\mathrm{L}_{\mathrm{a}}=7.2 \mathrm{mH}$. Grid parameters: X/R: 7, F: $60 \mathrm{~Hz}, \mathrm{~V}_{\text {grid }}: 220 \mathrm{~V}$ and other parameters, DC link capacitor: $5100 \mu \mathrm{F}, \mathrm{DC}$ link voltage: $1100 \mathrm{~V}$, Type of load: inductive, Load power: $90 \mathrm{~kW}$.

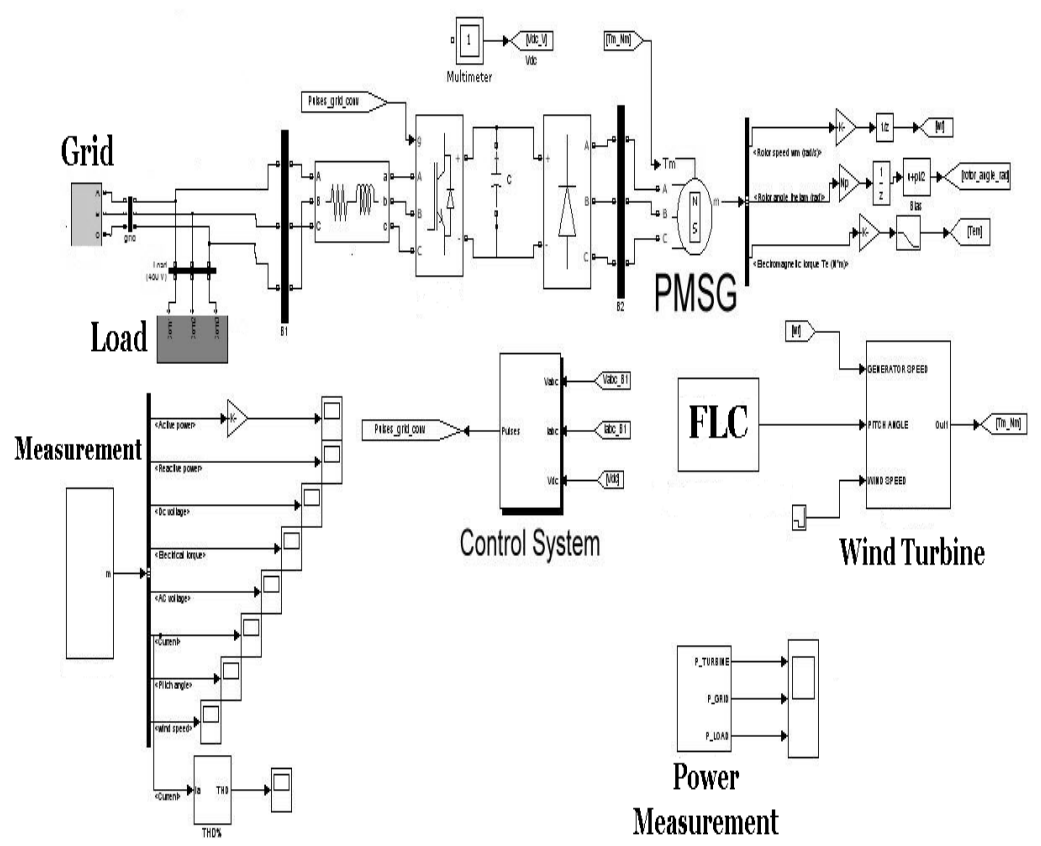

Figure 8. The block diagram of grid connected WPGS in Matlab/Simulink 


\subsection{Case Study}

In this case, the evaluation of FLC with comparing to conventional PI controller in pitch angle of WPGS is carried out. The dynamic performance of WPGS under variations of wind speed and load circumstances is investigated. There is no power exchange between WPGS and grid in normal condition.

During $0<\mathrm{t}<1 \mathrm{~s}$, the load power is $90 \mathrm{~kW}$ and at $\mathrm{t}=1 \mathrm{~s}$, it has $\% 25$ step increase in load that is constant until $\mathrm{t}=2 \mathrm{~s}$. Then, at $\mathrm{t}=3 \mathrm{~s}$, it has step decrease $40 \%$ in load power, that is constant until $\mathrm{t}=4 \mathrm{~s}$. Wind speed during $0<\mathrm{t}<5 \mathrm{~s}$ is $12 \mathrm{~m} / \mathrm{s}$ and at $\mathrm{t}=5 \mathrm{~s}$, it is reduced to $10 \mathrm{~m} / \mathrm{s}$. Then, during $5<$ $\mathrm{t}<7$, wind speed is $10 \mathrm{~m} / \mathrm{s}$ and after that, at $\mathrm{t}=7 \mathrm{~s}$, it is extremely increased to $19 \mathrm{~m} / \mathrm{s}$. By designing FLC, when wind speed is more than nominal speed $(12 \mathrm{~m} / \mathrm{s})$, turbine output power is increased by extremely increasing wind speed; however, with PI controller, the power is constant at a high level and in the presence of FLC, it is reduced to the nominal power and made smoother, thereby leading to the prevention of mechanical fatigue to generator.

Figure 9 shows the variation of wind speed in proposed system. Inverter output voltage is invariant, which is shown in Figure 10. The variation of pitch angle in the presence of FLC is depicted in Figure 11. As can be seen, in normal situations, the pitch angle is set as zero. At wind speeds above the rated wind, the extracted wind power has to be limited by increasing the pitch angle $(\beta)$. Figures 12 and 13 show the inverter output current with the PI controller and in the presence of FLC, respectively. It shows the effectiveness of fuzzy controller by increasing pitch angle. The exceeding power of wind turbine is limited and also, the inverter output current is reduced by FLC in comparison to PI controller. Figures 14 and 15 show the turbine output power with PI controller and in the presence of FLC according to variation of wind speed. By increasing the pitch angle via FLC, the exceeding power of wind turbine is limited, reaching to the nominal value. DC link voltage remains at a constant value $(1100 \mathrm{~V})$, thereby proving the effectiveness of the established P-Q controller as illustrated in Figure 16. The reactive power produced by the WPGS is regulated at zero that, the power factor maintained unity as shown in Figure 17. The grid current with PI controller and FLC are shown in Figures 18 and 19, respectively.

One of the most important aspects of using DG sources and connecting them to grid is keeping the THD at the minimum of its value. According to IEEE Std.1547.2003, it should be around 5\%. In THD curve, it is around 5\% to 7\%, which is shown Figure 20. Grid voltage is depicted in Figure 21. It can be observed from Figure 15, that pitch angle based on FLC can limit the exceeding output power of wind turbine. Therefore, by the reduction of output power of wind turbine, the injection of extra total active power to grid is declined. The exchange active powers among grid and WPGS are illustrated in Figures 22 and 23.

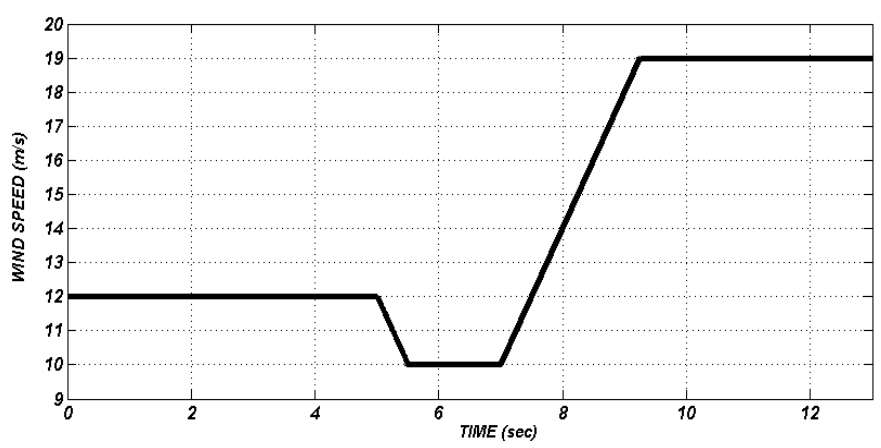

Figure 9. Variation of wind speed 
International Journal of Soft Computing, Mathematics and Control (IJSCMC), Vol. 3, No. 4, November 2014

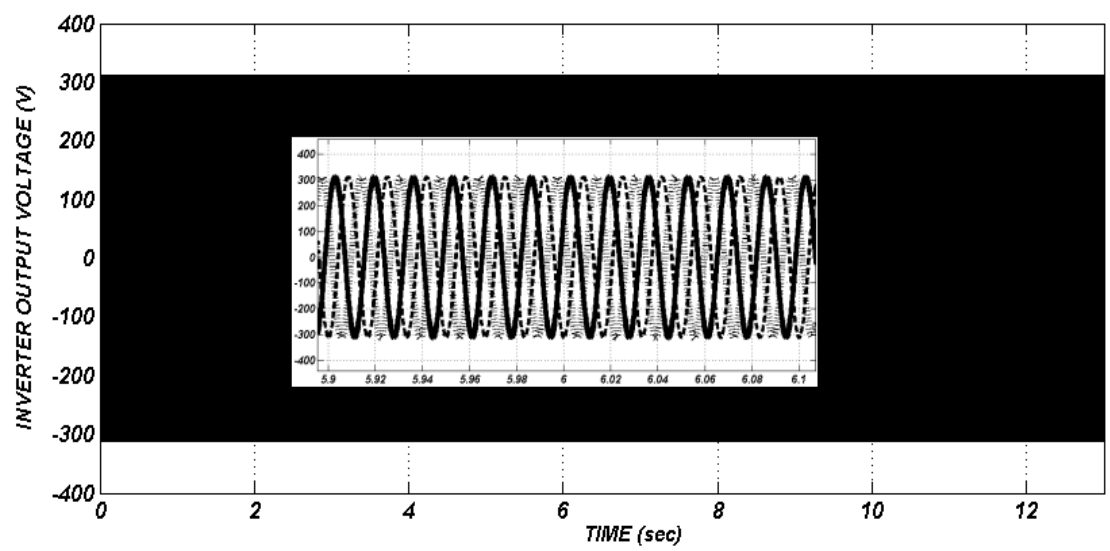

Figure 10. Inverter output voltage

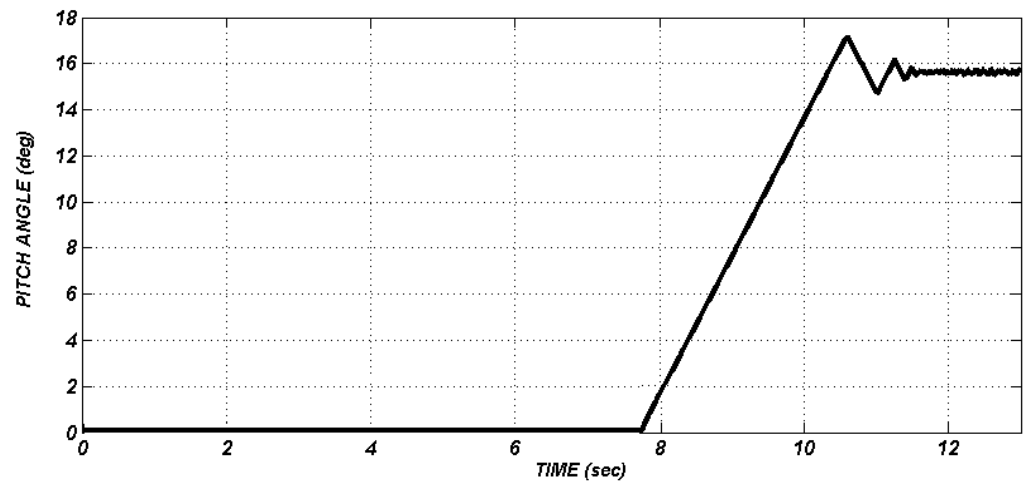

Figure 11. Variation of pitch angle by FLC

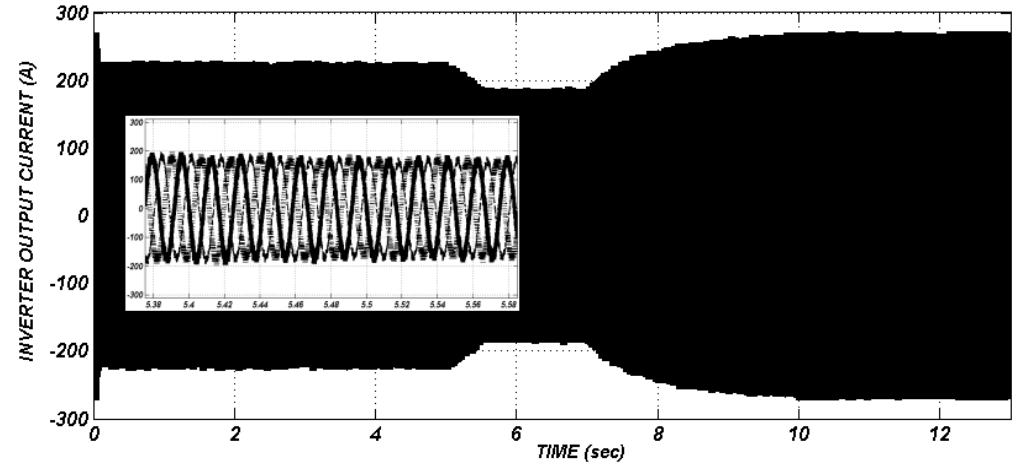

Figure 12. Inverter output current by PI controller 
International Journal of Soft Computing, Mathematics and Control (IJSCMC), Vol. 3, No. 4, November 2014

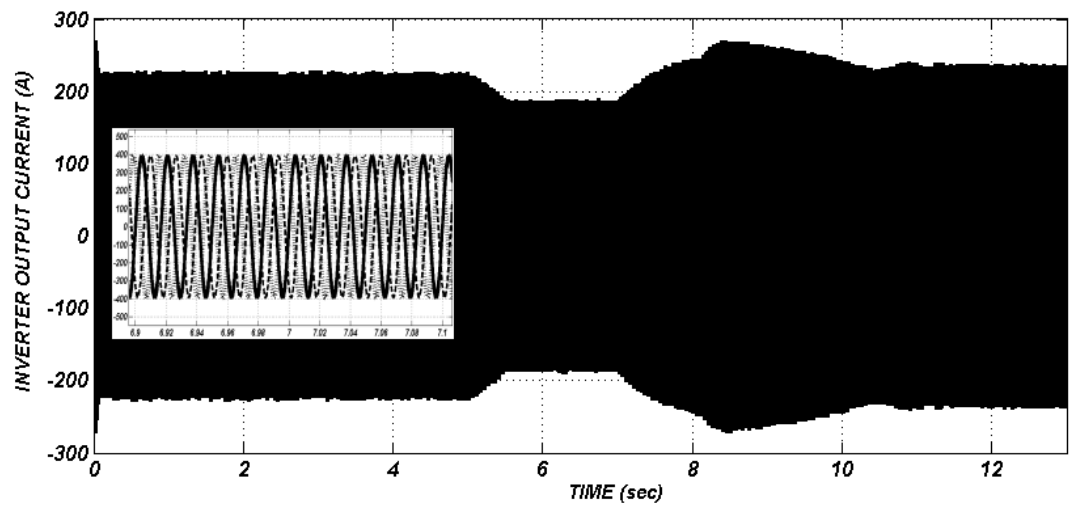

Figure 13. Inverter output current by FLC

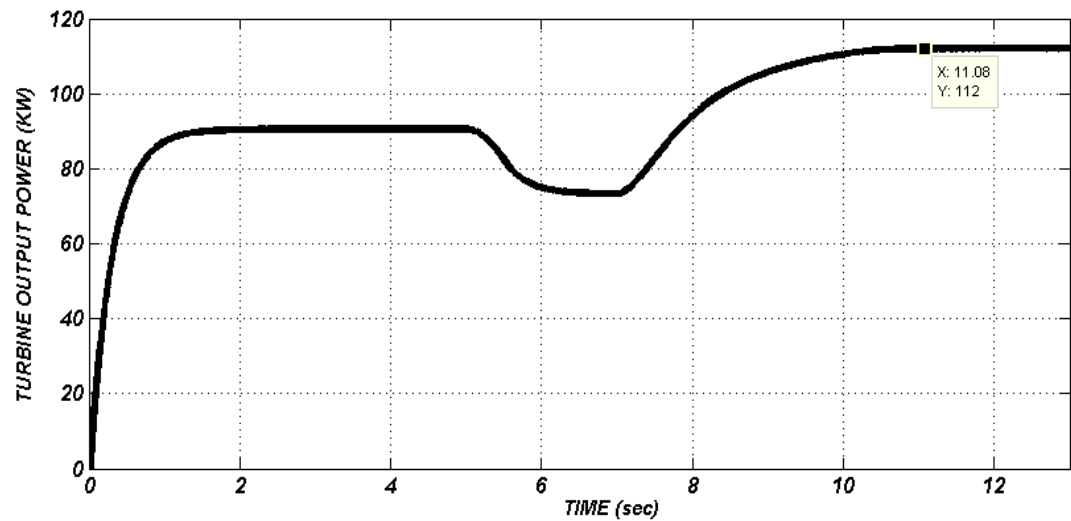

Figure 14. Turbine output power by PI controller

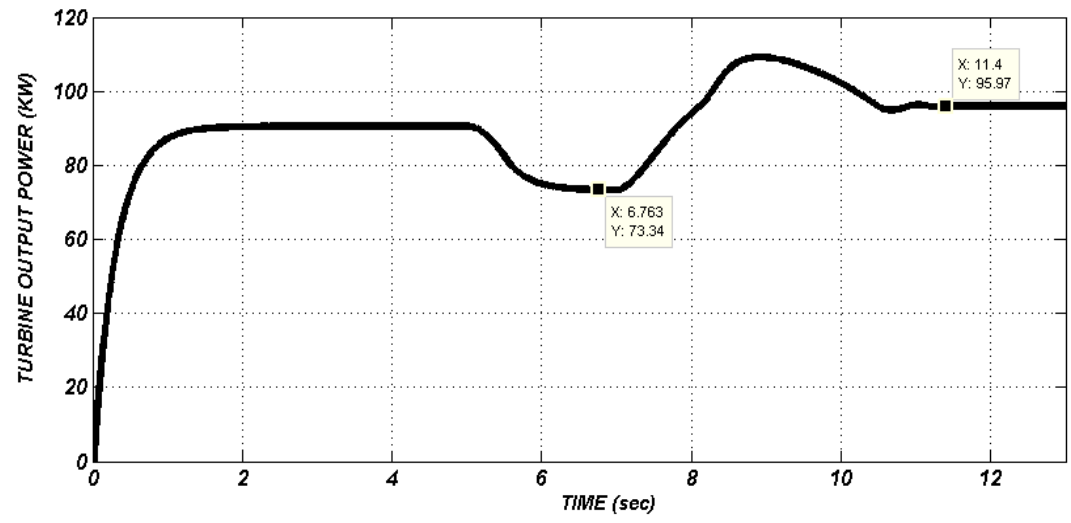

Figure 15. Turbine output power by FLC 
International Journal of Soft Computing, Mathematics and Control (IJSCMC), Vol. 3, No. 4, November 2014

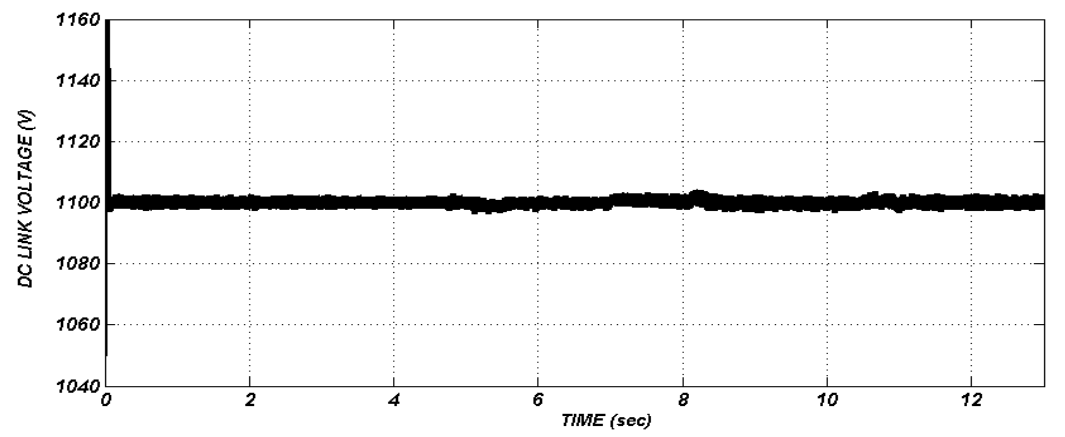

Figure 16. DC link voltage

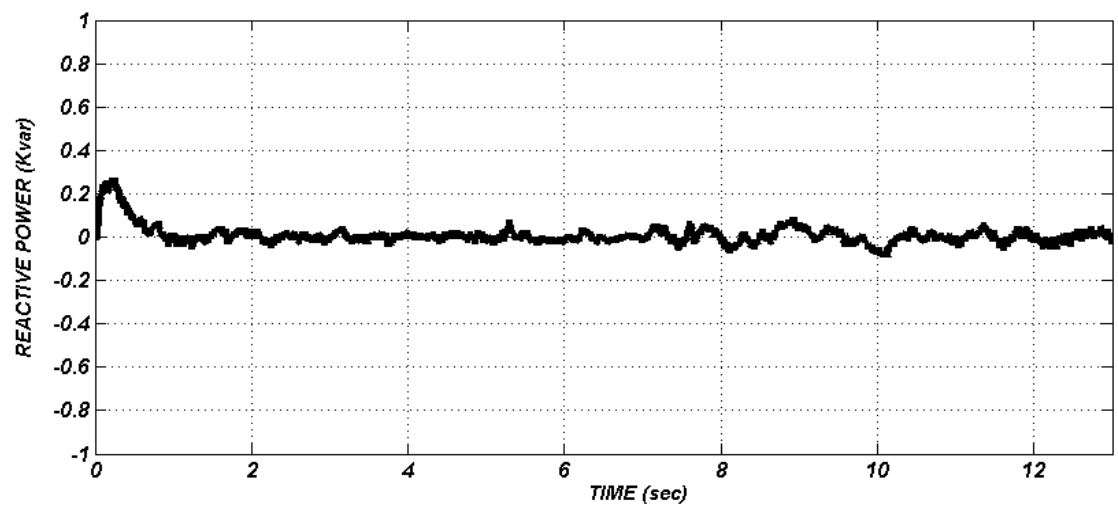

Figure 17. Reactive power

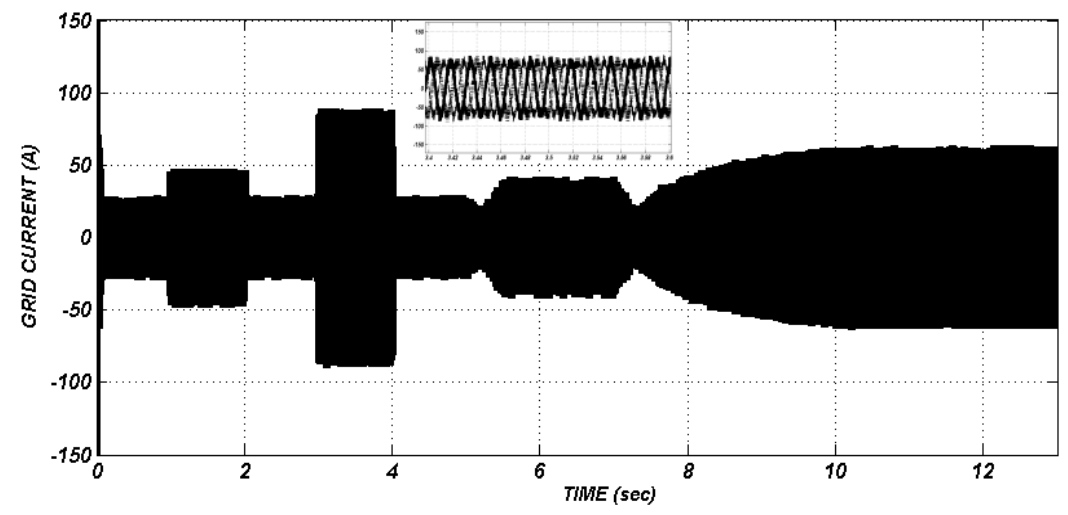

Figure 18. Grid current by PI controller 
International Journal of Soft Computing, Mathematics and Control (IJSCMC), Vol. 3, No. 4, November 2014

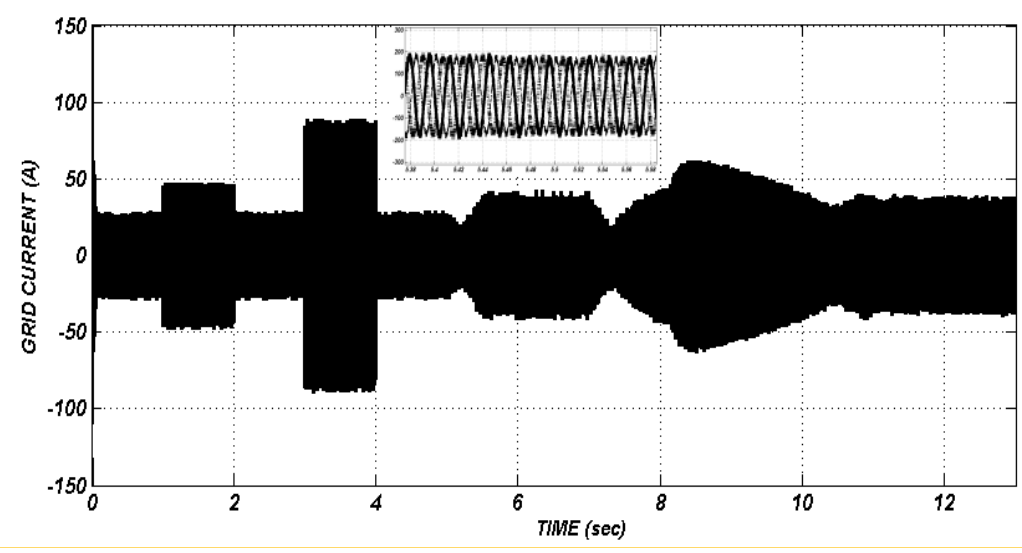

Figure 19. Grid current by FLC

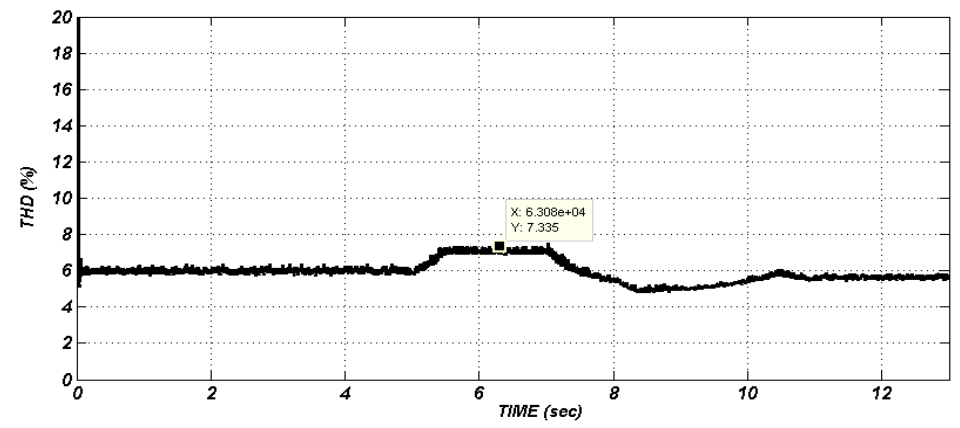

Figure 20. THD (\%)

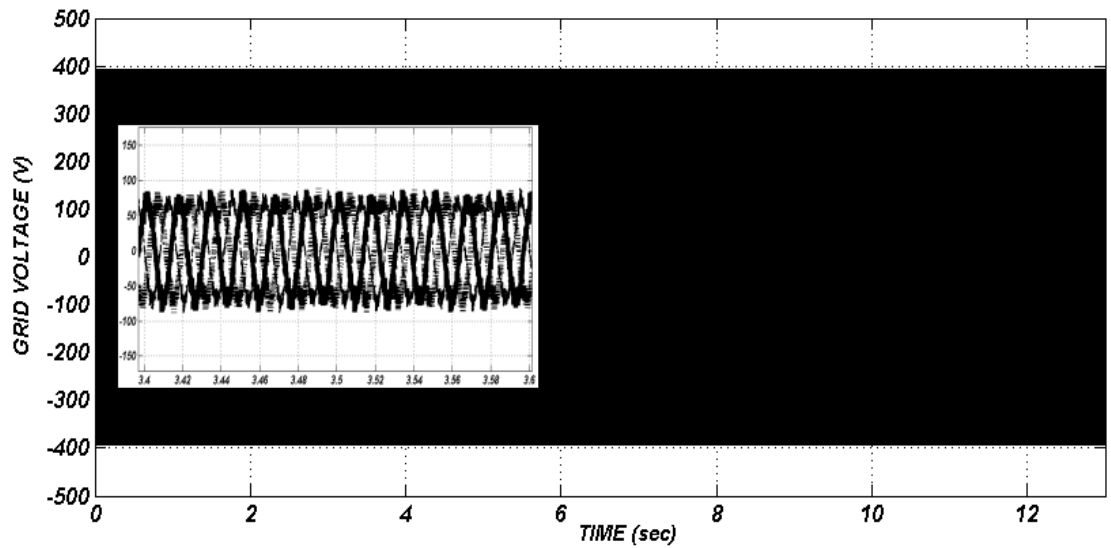

Figure 21. Grid voltage 


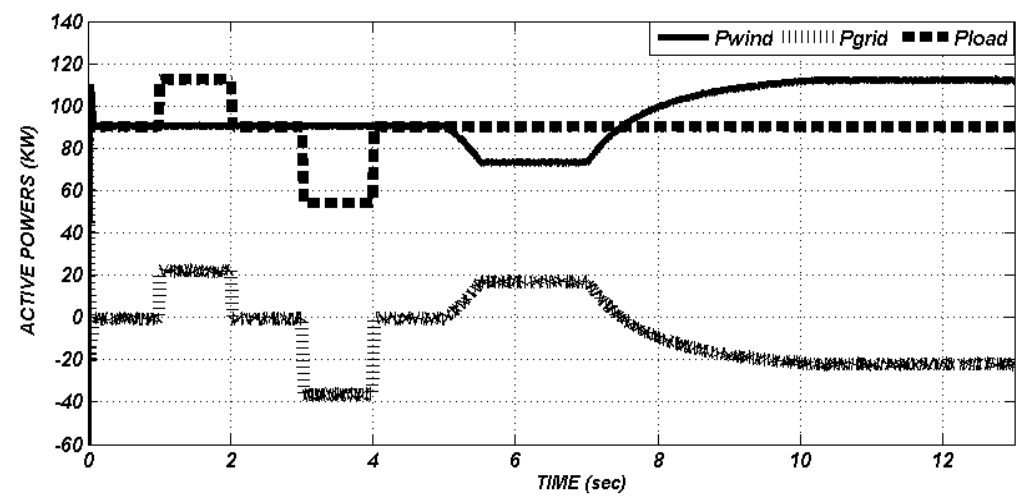

Figure 22. Active powers by PI controller

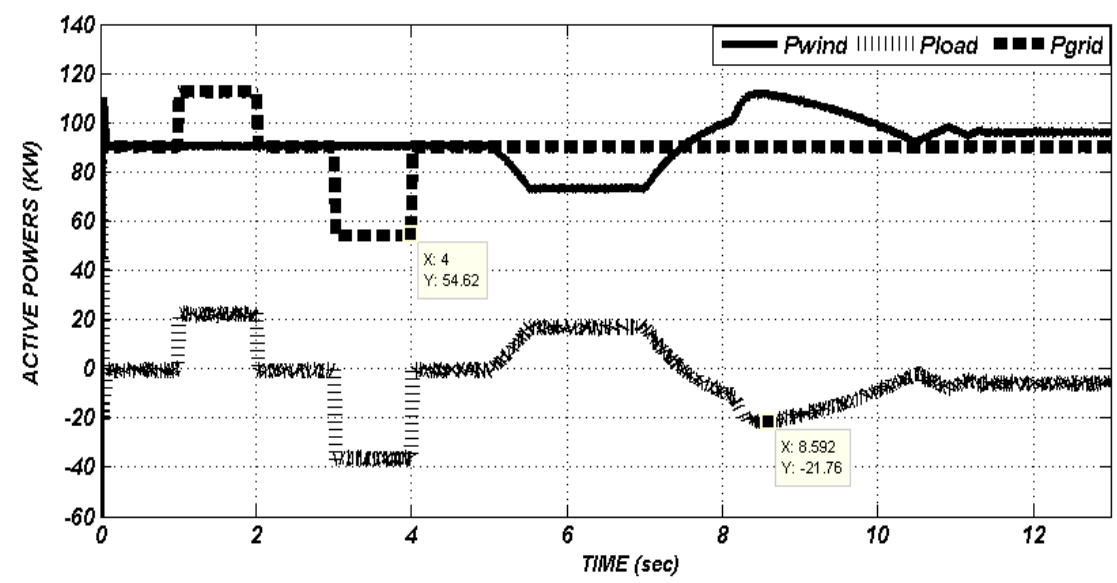

Figure 23. Active powers by FLC

\section{CONCLUSIONS}

In the proposed paper, the dynamic responses of grid connected wind turbine using PMSG under load circumstances and variation of wind speed was carried out. Control strategy and precise modelling of DC/AC grid connected converter was presented. Inverter adjusted the DC link voltage and active power was fed by $\mathrm{d}$-axis and reactive power was fed by q-axis (using P-Q control mode).

The simulation results indicated that using FLC could dramatically reduce the disadvantages of PI method. Moreover, the presented FLC in the WPGS, by adding wind speed as an input signal, could have faster and smoother, prevent more mechanical fatigue and also, the dynamic performance of wind turbine could be improved. On the other hand, by increasing pitch angle via FLC, the exceeding power of wind turbine was limited, reaching to the nominal value and reduced inverter output current. Therefore, by the reduction of injected output power of wind turbine, the injection of extra total active power to grid was declined. It was clear that, the WPGS by applying FLC in pitch angle and also, with the cooperation of grid could easily meet the load demand. 
International Journal of Soft Computing, Mathematics and Control (IJSCMC), Vol. 3, No. 4, November 2014

\section{REFERENCES}

[1] M.Izadbakhsh, M.Gandomkar, A.Rezvani and A.Ahmadi,"Short-term resource scheduling of a renewable energy based micro grid”, Renewable Energy,Vol.75, pp.598-606, 2015.

[2] A.Rezvani, M.Gandomkar, M.Izadbakhsh and A.Ahmadi,'Environmental/economic scheduling of a micro-grid with renewable energy resources', Journal of Cleaner Production,Vol.87, pp. 216-226, 2015.

[3] P. Vas, Electrical Machines and Drives: A Space Vector Theory Approach. New York, USA: Oxford Univ. Press, 1992.

[4] J. F. Manwell, J. G. Mcgowan, A. L. Rogers, Wind Energy Explained: Theory, Design and Application, John Wiley \& Sons Ltd, Chichester, 2002.

[5] M.G. Simoes, B.K. Bose, and R.J. Spiegel, "Fuzzy Logic Based Intelligent Control Of A Variable Speed Cage Machine Wind Generation System," IEEE Transactions On Power Electronics, vol. 12, no 1, pp.87-95, 1997.

[6] E.B.Muhandoa, T. Senjyua, H. Kinjob and T. Funabashi, "Augmented LQG controller for enhancement of online dynamic performance for WTG system”, Renewable Energy, vol.33, pp.19421952, 2008.

[7] K.Y. Lo, Y. M. Chen, and Y. R. Chang,' MPPT Battery Charger for Stand-Alone Wind Power System', IEEE transactions on power electronics, vol. 26, no. 6, pp. 1631 - 1638, 2011.

[8] J.Y.M. Cheung, A.S. Kamal," Fuzzy Logic Control of refrigerant flow”, UKACC International Conference on Control, Conference Publication,Vol.96, No. 427 ,pp. 2-5 ,September 1996.

[9] Gaurav, A. Kaur," Comparison between Conventional PID and Fuzzy Logic Controller for Liquid Flow Control: Performance Evaluation of Fuzzy Logic and PID Controller by Using MATLAB/Simulink", International Journal of Innovative Technology and Exploring Engineering (IJITEE), Vol.1, no.1, pp. 84-88, June 2012.

[10] M. Chinchilla, S. Arnaltes, and J. C. Busgos, "Control of permanent magnet synchronous generators applied to variable-speed wind-energy systems connected to the grid," IEEE Trans. Energy Convers., vol. 21, no. 1, pp. 130-135, Mar. 2006.

[11] S. Morimoto, T. Nakamura, and Y. Takeda, " Power maximization control of variable-speed wind generation system using permanent magnet synchronous generator,” IEEJ Trans. Power Energy, vol. 123, no. 12, pp. 1573-1579, 2003.

[12] N. A. Cutululis, E. Ceanga, A. D. Hansen, and P. Sørensen, "Robust multi-model control of an autonomous wind power system," Wind Energy, vol. 9, no. 5, pp. 399-419, 2006.

[13] X. Lingfeng, Y. Xiyun, L. Xinran, and X. Daping, "Based on adaptive fuzzy sliding mode controller," in Intelligent Control and Automation, WCICA 7th World Congress on china, pp. 2970-2975, 2008.

[14] C. A. M. Amendola and D. P. Gonzaga, "Fuzzy-Logic Control System of a Variable-Speed VariablePitch Wind-Turbine and a Double-Fed Induction Generator", in Intelligent Systems Design and Applications, Seventh International Conference on Brazil, pp. 252-257, 2007.

[15] T. Senjyu, R. Sakamoto, N. Urasaki, T. Funabashi, and H. Sekine, "Output power leveling of wind farm using pitch angle control with fuzzy neural network," in Power Engineering Society General Meeting, IEEE, Japan, pp.1- 8,2006.

[16] X. Yao, Ch. Guo and Z. Xing, Y. Li, S. Liu', Variable Speed Wind Turbine Maximum Power Extraction Based on Fuzzy Logic Control', International Conference on Intelligent Human-Machine Systems and Cybernetics ,China, pp.202 - 205,2009.

[17] Q. Zeng , L. Chang , R. Shao ," Fuzzy-logic-based maximum power point tracking strategy for PMSG variable-speed wind turbine generation systems ", , Electrical and Computer Engineering, CCE Canadian Conference on, pp. 405-410,2008.

[18] T.L.Van , D.CH.Lee ,' Output power smoothening of variable - speed wind turbine systems by pitch angle control', 'IPEC 2012 Conference on Power \& Energy, pp.166-171, 2012.

[19] A. Kahrobaeian, Y.A.-R.I. Mohamed , "Analysis and Mitigation of Low-Frequency Instabilities in Autonomous Medium-Voltage Converter-Based Microgrids With Dynamic Loads ”, IEEE Trans. on Industrial Electronics ,vol. 61, no.4, pp. 1643 - 1658, 2014.

[20] C.T. Lee , R.P. Jiang , P.T. Cheng , "A Grid Synchronization Method for Droop-Controlled Distributed Energy Resource Converters”, IEEE Trans. on Industry Application, Vol.49, no.2, pp. 954 - 962, 2013. 
International Journal of Soft Computing, Mathematics and Control (IJSCMC), Vol. 3, No. 4, November 2014

[21] Md. Arifujjaman, "Modeling, Simulation and Control of Grid Connected Permanent Magnet Generator (PMG)-based Small Wind Energy Conversion System” IEEE Electrical Power \& Energy Conference, Canada, pp.1-6, 2010.

[22] Z. Lubosny, ' Wind Turbine Operation in Electric Power Systems', Berlin, Springer, 2003.

[23] A. Uehara , A.Pratap , T. Goya , T. Senjyu, A. Yona , N. Urasaki and T. Funabashi, "A Coordinated Control Method to Smooth Wind Power Fluctuations of a PMSG-Based WECS" IEEE Transactions on Energy Conversion, Vol. 26, No. 2, pp. 550-558, June 2011.

[24] M. Rosyadi , S. M. Muyeen , R. Takahashi , J. Tamura' Fuzzy-PI Controller Design for PM Wind Generator to Improve Fault Ride Through of Wind Farm', International journal of renewable energy research Marwan Rosyadi et al., Vol.3, No.2,pp.308-314, 2013.

[25] C. Krause, 'Analysis of electric machinery', 2nd Edition, United States of America: Willey, 2002.

[26] L. barote, C. marinescu 'Modeling and Operational Testing of an Isolated Variable Speed PMSG Wind Turbine with Battery Energy Storage'” Advances in Electrical and Computer Engineering, Vol. 12, No. 2, pp.81-88, 2012.

[27] Y. oner, N. bekiroglu, S. ozcira 'Dynamic Analysis of Permanent Magnet Synchronous Generator with Power Electronics ', Advances in Electrical and Computer Engineering, Vol. 10, No. 2, pp.11$15,2010$.

[28] M. Rosyadi, S.M. Muyeen, R. Takahashi, J. Tamura, "Transient stability enhancement of variable speed permanent magnet wind generator using adaptive pi-fuzzy controller," in Proc. Trondheim Power Tech. Conf, Germany, pp.1-6,2011.

[29] L. X. Wang, " A course in fuzzy systems and control', New Jersey: Prentice Hall, 1997.

[30] A. Rolan , A. Luna, G. Vazquez, D. Aguilar and G. Azevedo , "Modeling of a Variable Speed Wind Turbine with a Permanent Magnet Synchronous Generator", IEEE International Symposium on Industrial Electronics (ISIE 2009), Korea , July 5-8, pp. 734-739, 2009.

\section{Authors}

MaziarIzadbakhshwas born in Tehran, Iran in 1989. Hereceived his B.Sc and M.Sc degrees in electrical power engineering from Islamic Azad University,Saveh Branch, Iran in 2011 and 2014, respectively. His research interests include the renewable energy, microgrid, Power system planning and operation, hybrid systemand optimization

MajidGandomkar was born in the Saveh, Iran. He received PHD degree of Electrical Engineering from Science and Research Branch of Islamic Azad University. His research interests include distribution systems, DG systems, optimization. Now, he is Assistant Professor at Islamic Azad University, Saveh Branch.

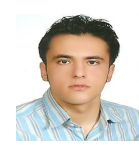

AlirezaRezvaniwas born in Tehran, Iran in 1989. Hereceived his B.Sc and M.Sc degrees in electrical power engineering from Islamic Azad University,Saveh Branch, Iran in 2011 and 2014, respectively. His research interests include the renewable energy, microgrid,Power system planning and operation, hybrid systemand optimization.
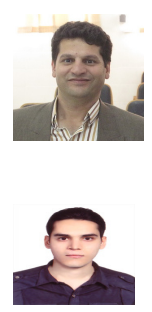